\title{
Generalization of calculation methods for gender indices in demographic and social statistics
}

Kateryna Serhiivna

Akbash

Volodymyr Vynnychenko Central

Ukrainian State Pedagogical

University, Ukraine

E-mail:

kateryna.akbash@gmail.com

Natalia Oleksiivna

Pasichnyk

Volodymyr Vynnychenko Central

Ukrainian State Pedagogical

University, Ukraine

E-mail: pasichnyk1809@gmail.com

Renat Yaroszlavovics

Rizhniak

Volodymyr Vynnychenko Central

Ukrainian State Pedagogical

University, Ukraine

E-mail: rizhniak@gmail.com

Keywords: gender parity,

gender asymmetry, statistical methodology, demo-

graphic statistics,

social statistics,

Erasmus+ Project:

Gender Studies Curriculum
Currently, theoretical and practical approaches to gender issues are at a developmental stage. An important issue in gender statistics is the correct application of simple gender indices. This topic should be of interest to scholars and social workers engaged with gender issues. Due to the fact that gender parity/asymmetry indices give different results in different spheres of application, there is a need to develop separate methodological approaches for applying the indices to demographic and social statistics. In the research presented, mathematical methods were used to obtain complete and accurate quantitative characteristics of simple gender indicators. Methods of statistical observations, statistical groupings are used in the process of collecting, systematizing, and processing data. Results are graphically illustrated. It was established that when calculating gender indices for demographic statistics, the use of simple Gender Parity and Gender Asymmetry Indices is correct, and when calculating gender indices for social statistics, specific corresponding modifications should be applied which adjust for general demographic trends when analysing the gender distributions for selected social spheres. In exceptional cases (when demographic indices of the number of men and women are comparable), gender parity indices can be used when calculating the gender indices for social spheres. Therefore the results indicate that the analysis of gender parity/asymmetry requires separate methodological approaches for demographic and social statistics. 


\section{Introduction}

Currently, theoretical and practical approaches to gender issues are at a developmental stage. The main conceptual idea of gender is that it is a social construct, influenced by the culture and traditions of society, and reflects the society's conception of differences between women and men. The development of the gender approach led to the revision of existing methodologies in social and socio-human sciences and, accordingly, the application of new methods. As a result, the trend of knowledge formation that is up-to-date on gender theory became widespread, applying an integrated approach (gender mainstreaming) to the issue of equality between women and men. Gender mainstreaming has been internationally recognized (Beijing Declaration and Platform for Action, 1995; Gender Mainstreaming Concept of the Economic and Social Council of the UN General Assembly, 1997; Conceptual Framework for Gender Mainstreaming of the Council of Europe, 1998; and the State Programme for the Promotion of Gender Equality, 2006, which was used as the basis of the Ukrainian Gender Policy). At the same time, some scholars point out the existence of significant contradictions between modern gender theory and the concept of gender mainstreaming which may negatively affect the development of mechanisms for the practical implementation of gender equality in society (Herbut 2012). In addition to the integrated approach to gender studies, there are other methods used depending on the objectives and the subject of the research.

One of these alternative methods is the theoretical method, which aims to organize the knowledge of gender on the principles of logical construction of a holistic concept, and to determine the purpose of this knowledge both in the system of social studies and within the framework of separate social sciences or the humanities. The theoretical method in gender studies facilitates the identification of the range of existing problems and the clarification of the subject of study. The method also determines the proper place of gender in modern humanities as a whole. The historical and genetic method in gender studies is characterized as a gender-oriented dimension of the historical process, a two-way approach for assessing historical events, situations and activities, and their consequences in a certain period and society. This method addresses events from the point of view of recognizing the interests and needs of both women and men. Social and psychological methods of studying gender include the study of socially constructed female and male roles and relationships, sexual characteristics, psychological characteristics, identity, etc. The empirical method of gender studies proves the existence and significance of objective facts, events and actions, and the manifestation of quantitative and qualitative parameters. The prognostic method in the study of gender addresses questions regarding gender development in the world (or a defined region) as a whole.

Regional Statistics, Vol. 8. No. 2. 2018: 170-183; DOI: 10.15196/RS080205 
The above methods of gender studies are closely connected with statistical methods featuring numerical indicators which reflect the fairness of distribution and use of national welfare and services among social groups, within a global context or within particular regions, taking into account gender. Gender statistics show social and demographic characteristics of specific groups, with reference to distinctions between women and men. Gender statistics are the key information source for monitoring the circumstances of women and men in the world (or specific regions); they facilitate the development of strategic solutions for social and economic policy to implement social equality. The simplest indices of gender statistics are the gender parity and gender asymmetry indices, which are widely used in the calculation of more complex indicators. Since these indices give differing results for the general population and for particular samples, there is a need to develop separate methodological approaches for using such indices in demographic and social statistics.

\section{Analysis of research and publications}

The main simple indices for assessing gender inequality are given in the 1999 UNESCO document. These are the gender parity index, gender gap figures, the gender segregation index, analysis of gender data on the basis of correlation fields, etc. The 2009 UIS document presents the methodology for calculating the Gender Parity Index for specific educational indicators, in particular the analysis of the proportion of girls to boys for particular levels of education and age groups. The method of applying the Gender Parity Index to educational indicators is discussed in the works of Bhattacharya (2013), Jana et al. (2014), and Huebler (2008). Some generalizations of these indices are set out in Akbash et al. (2017a, 2017b, 2017c), but more attention is paid to the qualitative content and analysis of gender indices. In Akbash et al. (2017b), the coefficient of gender asymmetry was introduced, which in our opinion is a convenient measure for graphically interpreting gender parity. The underlying idea: the method of calculating the coefficient of gender asymmetry was borrowed from biology, in particular from Anisimova (2015), where functional asymmetry was demonstrated on the basis of structural and functional differences between the left and right hemispheres of the human brain.

Complex indices are used for gender analysis which cover several fields of human activity simultaneously. Basically, these indices are calculated at country level and are used to rank countries according to their level of human development. The main complex indices for assessing gender equality at the national level are the Gender Development Index, Gender Empowerment Measure, Gender Inequality Index, Gender Equality Index, Global Gender Gap Index, and the Social Institutions and Gender Index. The methodologies for calculating these indices are mathematically complex and they often incorporate the Gender Parity Index in their intermediate calculation formulas. For example, in order to calculate the Global

Regional Statistics, Vol. 8. No. 2. 2018: 170-183; DOI: 10.15196/RS080205 
Gender Gap Index (WEF 2016), the Gender Parity Index is calculated, based on fourteen basic indicators of the country, and then further calculations are applied.

Most international reports that present the analyses of gender differences in countries and regions of the world highlight a number of key areas for gender analysis. For example, to calculate the Gender Equality Index, six main domains (work, money, knowledge, time, power and health) and two additional domains (intersecting inequalities and violence) are distinguished (GEI 2017). The Global Gender Gap Index is calculated using fourteen indicators in four areas: economic participation and career opportunities; education; health; and political rights and opportunities (WEF 2016). This list of indices and of the assessed areas can be extended; gender statistical analysis covers virtually all spheres of human activity and requires a clear methodology for assessing gender parity/asymmetry in each of these areas.

The objective of this study is to assess the peculiarities of application of simple gender indices and to test the theory that the analysis of gender parity/asymmetry requires various methodological approaches to demographic and social statistics.

We used various methods in our research, ensuring the objectivity of our results. Scientific methods of analysis and synthesis were used at different stages according to the subject of the research and the formulation of conclusions. Mathematical methods were used to obtain complete and accurate quantitative characteristics of simple gender indicators. Methods of statistical observation, statistical groupings, and estimation of errors in calculations were included in the statistical methods to collect, systematize, and process data. Simple gender indicators were graphically illustrated.

\section{Main research results}

\section{Assessment of gender parity}

The following basic terminology has been used. Demographic statistics (or population statistics) is a branch of demography which studies statistical patterns of the population. The subject of demographic statistics is the development of methods for statistical observation and measurement of demographic phenomena and processes, and collection and processing of statistical information on the population. Social statistics is a branch of statistical science that studies the quantitative aspects of mass social phenomena in order to identify patterns, interconnections, and trends. Social statistics studies the state structure and the political and economic system of a country, the social structure of a society, the standard of living of the population, the consumption of material goods and services, the conditions and nature of labour, social security, trade, housing, communal and transport services of the population, health care, education, culture and art, physical education and sports (Pidhornyi et al. 2016).

Regional Statistics, Vol. 8. No. 2. 2018: 170-183; DOI: 10.15196/RS080205 
Assessment of gender parity. In demographic statistics, the gender ratio is used to analyse the population of the world, global regions, individual countries, and smaller territorial units:

$$
G R=\frac{\text { population }_{m}}{\text { population }_{f}} \cdot 100 .
$$

The ratio shows the number of men for every 100 women in a certain region; population $_{m}$ is the number of males in the corresponding region, and population is $_{\text {in }}$ corresponding number of females.

Gender ratios may vary in different subgroups of a population. The gender ratio for new-borns will differ from that for the whole population or the elderly. Biologically, more boys are born than girls (104-107 boys for every 100 girls), but on average, women are more resistant to illnesses and live longer than men. Also, the tendency of men to enter riskier occupations and exhibit aggressive behaviour increases their chances of early death (UNECE 2016). Therefore, whereas the gender ratio of new-borns shows a higher number of boys than girls, the gender ratio for the elderly indicates more women than men (the value of the ratio calculation is less than 100).

In gender-neutral societies where men and women live in the same conditions, the gender ratio is from 98 to 100 (UNECE 2016). In 2015, the gender ratio for the whole world's population was 102, but values varied between different countries, from 274 in the United Arab Emirates to 85 in Latvia and Lithuania (86 in Ukraine). Gender differences are also significant in life expectancy (Uzzoli 2016).

The following indicators and methods are used to perform an analysis of gender parity: the Gender Parity Index, Gender Gap Index, Gender Asymmetry Index and correlation fields. Let us examine the methods for calculating these indices and illustrate the special features of their application.

The Gender Parity Index (GPI) is the ratio of the number of women to the number of men in a certain territorial region:

$$
G P I=\frac{\text { population }_{f}}{\text { population }_{m}} .
$$

This is the generally accepted Gender Parity Index, which was introduced by the UNESCO in 1999. Theoretically, the ratio may vary from 0 (in the absence of any women in the group) to infinity (in the absence of men in the group). In the case of absolute equality in numbers of women and men, the ratio is equal to 1 .

The Absolute Gender Gap ( $A G G$ ) is calculated as the difference between the number of men and the number of women in a certain territorial region:

$$
A G G=\text { population }_{m}-\text { population }_{f} \text {. }
$$

Results expressing that there are more women than men are denoted by a negative value.

Regional Statistics, Vol. 8. No. 2. 2018: 170-183; DOI: 10.15196/RS080205 
The Gender Asymmetry Index (GAI) is calculated as follows:

$$
\text { GAI }=\frac{\text { population }_{f}-\text { population }_{m}}{\text { population }_{f}+\text { population }_{m}}
$$

which yields values in the interval $[-1 ; 1]$. Where there are equal numbers of men and women in the group studied, GAI $=0$; where there are more women than men, GAI $>0$, and the closer the value of GAI is to 1, the bigger the imbalance towards women; where there are more men in the group, GAI $<0$ (the closer the value of GAI is to -1 , the greater the imbalance towards men).

Let us consider the demographic situation in some countries and analyse simple gender indices, in particular: GR, GPI, AGG, and GAI. Demographic indicators in Table 1 were taken from the work (WB 2017).

Table 1

Application of gender indices to the demographic profiles of selected countries, 2016

\begin{tabular}{|c|c|c|c|c|c|c|c|c|}
\hline & Country name & $\begin{array}{l}\text { Country } \\
\text { code }\end{array}$ & $\begin{array}{c}\text { Female } \\
\text { population }\end{array}$ & $\begin{array}{c}\text { Male } \\
\text { population }\end{array}$ & GR & GPI & AGG & GAI \\
\hline 1 & 2 & 3 & 4 & 5 & 6 & 7 & 8 & 9 \\
\hline 1 & $\begin{array}{l}\text { United Arab } \\
\text { Emirates }\end{array}$ & ARE & $2,524,948$ & $6,744,664$ & 267 & 0.37 & $4,219,716$ & -0.46 \\
\hline 2 & India & IND & $637,879,447$ & $686,291,907$ & 108 & 0.93 & $48,412,460$ & -0.04 \\
\hline 3 & China & $\mathrm{CHN}$ & $668,291,578$ & $710,373,422$ & 106 & 0.94 & $42,081,844$ & -0.03 \\
\hline 4 & Canada & CAN & $18,285,148$ & $18,001,277$ & 98 & 1.02 & $-283,871$ & 0.01 \\
\hline 5 & United States & USA & $163,233,094$ & $159,894,419$ & 98 & 1.02 & $-3,338,675$ & 0.01 \\
\hline 6 & Tunisia & TUN & $5,769,883$ & $5,633,365$ & 98 & 1.02 & $-136,518$ & 0.01 \\
\hline 7 & Greece & GRC & $5,456,150$ & $5,290,590$ & 97 & 1.03 & $-165,560$ & 0.02 \\
\hline 8 & Japan & JPN & $64,962,126$ & $62,032,385$ & 95 & 1.05 & $-2,929,741$ & 0.02 \\
\hline 9 & Moldova & $\mathrm{MDA}$ & $1,846,518$ & $1,705,482$ & 92 & 1.08 & $-141,036$ & 0.04 \\
\hline 10 & $\begin{array}{l}\text { Russian } \\
\text { Federation }\end{array}$ & RUS & $77,268,128$ & $67,074,268$ & 87 & 1.15 & $-10,193,860$ & 0.07 \\
\hline 11 & Ukraine & UKR & $24,201,697$ & $20,802,948$ & 86 & 1.16 & $-3,398,749$ & 0.08 \\
\hline
\end{tabular}

The countries in the table are sorted by the value of their gender ratio. The four indicators (columns 6-9) illustrate each country's demographic situation in different ways.

The most convenient indicator for visual illustration is GAI, since values are restricted to the symmetric deviations from zero to 1 in the case of female predominance, and zero to -1 in the case of male predominance (see Figure 1.).

Regional Statistics, Vol. 8. No. 2. 2018: 170-183; DOI: 10.15196/RS080205 
Visualization of GAI data (per Table 1)

Figure 1

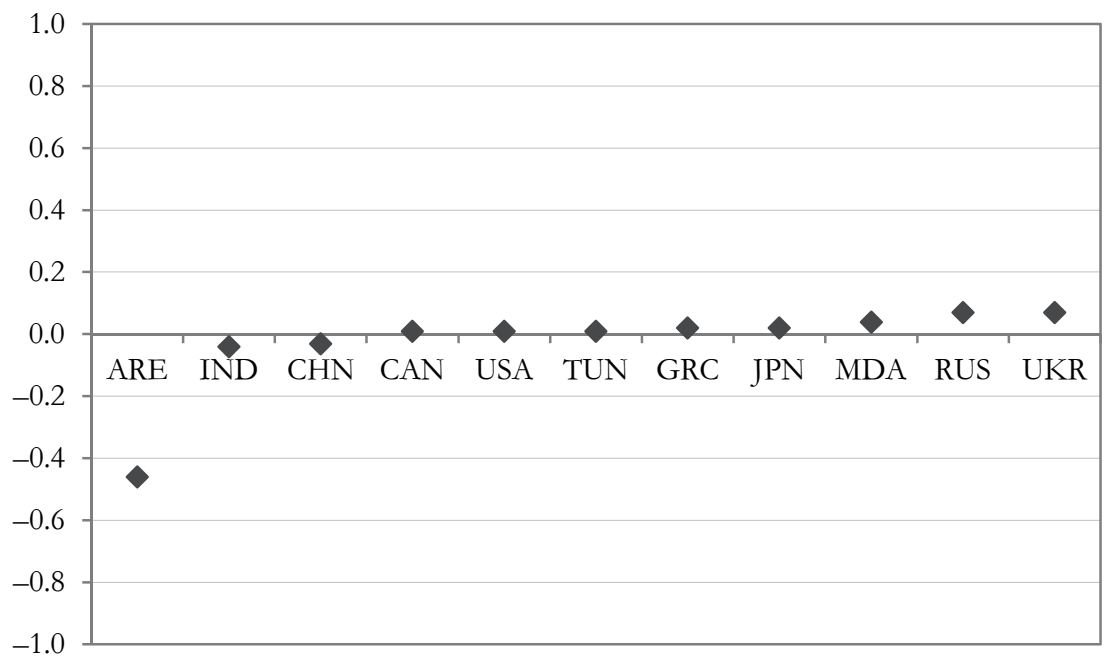

Note: For country codes, see Table 1.

In the first three countries of Table 1, we see a predominance of men in the population. The GPI values illustrate the same, since all are less than 1. AGG shows how many more men than women there are in the country. The minus coefficient of asymmetry also shows the predominance of men.

The mid-ranked countries (Canada, United States, Tunisia, Greece, Japan) are closest to parity in the country's demographic indicators, but there is a slight predominance of females in their populations.

The lowest-ranked countries (all former Soviet states, Moldova, Russian Federation, and Ukraine) are characterized by high gender asymmetry with predominantly female populations.

\section{Assessment of specific gender parity}

There are a number of indices for the assessment of gender parity for specific subgroups of a population.

The calculation of indicators of gender parity for sub-groups is based on the specific values of the structure (SVS) for that sub-group, which characterize the specific weights of the component elements in the sum total. SVS values are determined by the formula:

$$
\mathrm{SVS}=\frac{\text { share of totality of coverage }}{\text { overall totality of coverage }}
$$


Thess set of specific values of the structure illustrate the phenomenon being studied (Pidhornyi et al. 2016). We introduce the following ratios based on the SVS:

$$
\text { ratio }_{f}=\frac{\text { number }_{-} s p h_{f}}{\text { population }_{f}} ; \quad \text { ratio }_{m}=\frac{\text { number }_{-} s p h_{m}}{\text { population }_{m}},
$$

where number_sph $h_{f}$ is the number of females (males) who have a certain feature chosen for the analysis of a certain social sphere in a certain region (i.e. the subgroup); populationf is the total female (male) population in this region.

Specific Gender Parity Index (GPI $I_{\text {sph) }}$. The articles (Akbash et al. 2017a, 2017b, 2017c) introduced the specific gender parity index which is calculated in the following way:

$$
G P I_{s p h}=\frac{\text { ratio }_{f}}{\text { ratio }_{m}} .
$$

This index identifies how many times larger/smaller the proportion of women with a certain feature in the social sphere of the study is than the corresponding proportion of men. Thus, $G P I_{\text {sph }}$ changes within the limits $[0 ; \infty]$, and is a qualitative value representing the ratio of the distribution of certain features in gender groups. The cases where GPI sph we will call parity; cases where $G P I_{\text {sph }}$ is not equal to 1 we will describe as lacking parity. (If ( $G P I_{\text {sph }}>1$ then the ratio for women is greater than the ratio for men; if $G P I_{s p h}<1$ the opposite is true.)

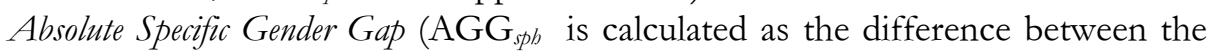
proportion of men with a selected trait among the total number of men in the selected demographic group and the equivalent proportion for women (expressed as a percentage):

$$
A G G_{s p h}=\left(\text { ratio }_{m}-\text { ratio }_{f}\right) \cdot 100 \% .
$$

This index is meaningful if the number of men and women in the corresponding demographic groups is approximately the same $\left(\right.$ population $_{m} \approx$ population $_{f}$ ). The index characterizes whether the percentage of men with a certain feature is larger or smaller than the corresponding proportion of women.

Specific Gender Asymmetry Index $G A I_{\text {sph }}$ is calculated using the proportion of women with a certain feature from the relevant demographic group, ratiof and the equivalent proportion of men, ration:

$$
\text { GAI }_{\text {sph }}=\frac{\text { ratio }_{f}-\text { ratio }_{m}}{\text { ratio }_{f}+\text { ratio }_{m}} .
$$

Thus, $G A I_{s p h}$ values will fall between the limits $[-1 ; 1]$, and yield a qualitative comparison of the distribution of certain features within gender groups. Cases where $G A I_{\text {sph }}=0$ we will describe as exhibiting symmetry between the proportions of men and women, and where the value is different to zero, will be described as asymmetrical. (if $G A I_{\text {sph }}>0$, the proportion for women exceeds that for men, and in the opposite case the proportion for men is greater.)

Having made elementary changes we can see the connection between specific gender parity index $G P I_{s p h}$ and specific gender asymmetry index $G A I_{s p b}$. Thus:

Regional Statistics, Vol. 8. No. 2. 2018: 170-183; DOI: 10.15196/RS080205 


$$
G A I_{s p h}=1-\frac{2}{G P I_{s p h}+1} \quad \text { or } \quad G P I_{s p h}=\frac{2}{1-G A_{s p h}}-1 .
$$

We shall now examine the following questions: 1) how universal is the application of the indices $G P I_{s p h,}, A G G_{s p h}, G A I_{s p h}$ and the indices GPI, AGG or GAI; 2) how wide or specific is their scope of application; and 3) how correct will their results be?

To do this, we demonstrate the application of the indices $G P I_{\text {sph }}, A G G_{s p h,} G A I_{\text {sph }}$ and the indices GPI, AGG, GAI to data arrays of different sizes in an arbitrary sphere. The first example relates to the ratio of female to male groups enrolled in primary education in different regions of the world.

Data will be limited to the following regions: the Kirovohrad region of Ukraine, the whole of Ukraine, Europe \& North America (UNESCO Region (UNESCO 2017)), and the whole world. Table 2 presents numerical values for the number of persons who were elementary school pupils in 2012 in each of the specified regions, a breakdown of those persons by gender, general demographic indicators and population distributions by gender of the Kirovohrad region of Ukraine, Ukraine, Europe \& North America, and the world (2012). (Data on education indicators were taken from (UNECE 2012), demographic indicators were obtained from (WB 2017), all data for the Kirovohrad region were obtained from (DSKR 2016).)

Table 2

\section{Gender indices for enrolment in primary education for arrays of different sizes, 2012}

\begin{tabular}{|c|c|c|c|c|}
\hline Denomination & $\begin{array}{l}\text { Kirovohrad } \\
\text { region }\end{array}$ & Ukraine & $\begin{array}{c}\text { Europe \& } \\
\text { North America }\end{array}$ & The world \\
\hline \multicolumn{5}{|c|}{ Children in primary school } \\
\hline number_sph $h_{f}$ & 16,932 & 775,316 & $35,793,423$ & $339,733,393$ \\
\hline number_sph $m$ & 17,456 & 809,066 & $40,400,077$ & $371,557,319$ \\
\hline \multicolumn{5}{|l|}{ General demography } \\
\hline population $_{f}$ & 539,900 & $24,549,634$ & $620,365,541$ & $3,516,939,678$ \\
\hline populationm $_{m}$ & 456,100 & $21,043,666$ & $588,555,526$ & $3,580,460,987$ \\
\hline \multicolumn{5}{|l|}{ Simple gender indices } \\
\hline GPI & 0.97 & 0.96 & 0.89 & 0.91 \\
\hline$A G G$ & 524 & 33,750 & $4,606,654$ & $31,823,926$ \\
\hline$G A I$ & -0.02 & -0.02 & -0.06 & -0.04 \\
\hline$G P I_{s p h}$ & 0.82 & 0.82 & 0.84 & 0.93 \\
\hline$A G G_{s p h}$ & 0.0069 & 0.0069 & 0.0109 & 0.0072 \\
\hline$G A I_{s p h}$ & -0.10 & -0.10 & -0.09 & -0.04 \\
\hline
\end{tabular}


In the mathematical sense of the concept of a multitude, the enumerated regions are consecutive subsets (and related by the inclusion of the sets, when moving from the region with the largest data array to the one with the smallest). Thus, the demographic data array for the population of the Kirovohrad region is a subset of the data array for the population of Ukraine. The data array of the population of Ukraine is included in the data array of Europe \& North America, which is in turn included in the data array for the world. (The same is true for the relationship between data arrays for primary school education.)

This example demonstrates the incorrect application of indices GPI, AGG, and GAI as non-demographic indicators. That is, the calculation of parity indices for education indicators was reduced to the following simplified formulas:

$$
\begin{gathered}
G P I=\frac{\text { number }_{s p h_{f}}}{\text { number }_{s p h_{m}}} ; \\
A G G=\text { number }_{s p h_{m}}-\text { number }_{s p h_{f}} ; \\
G A I=\frac{\text { number }_{s p h_{f}}-\text { number }_{s p h_{m}}}{\text { number }_{s p h_{f}}+\text { number }_{s p h_{m}}} .
\end{gathered}
$$

From these simple gender indices in Table 2 we see that for the world data array, the coefficients GAI and $G P I_{\text {sph }}$ work equally (values for both are -0.04), and the indices for GPI and $G P I_{\text {sph }}$ are close (with the values 0.91 and 0.93 respectively). Similarly close results are not observed for the data arrays of smaller regions. In the Kirovohrad region and Ukraine the difference in the indices is: for GPI and $G P I_{\text {sph }}$ $0.14-0.15$, and for GAI and $G A I_{\text {sph }} 0.08$. Lesser differences are observed in the indices for Europe \& North America, 0.05 and 0.03 respectively. In other words, to calculate gender parity and gender asymmetry among primary school children around of the world we may apply both formulas (7) and (9), as well as simplified

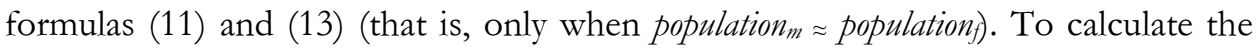
same indices among primary school children in other regions (with a smaller data array), it is expedient to use formulas (7) and (9), since they give results that correspond to the demographic situation in the corresponding territorial region. Otherwise, we will get results that ignore the distortive influence of underlying demographic gender ratios.

Let us consider another example connected with the identification of ratios between female and male groups, using data for 2016 which represented the subgroup of those individuals who are economically active, and all individuals in the general population who are more than 15 years old. The same territories' data arrays will be used: the Kirovohrad region of Ukraine, all Ukraine, Europe \& North America, and the world (Table 3). The data are obtained from (WB 2012).

Regional Statistics, Vol. 8. No. 2. 2018: 170-183; DOI: 10.15196/RS080205 
Table 3

Gender indices for arrays of different sizes

(Labour force participation rate 15+), 2016

\begin{tabular}{|c|c|c|c|c|}
\hline Denomination & $\begin{array}{l}\text { Kirovohrad re- } \\
\text { gion }\end{array}$ & Ukraine & $\begin{array}{l}\text { Europe and } \\
\text { North America }\end{array}$ & The world \\
\hline \multicolumn{5}{|c|}{ Economically active population $15+$} \\
\hline number_sph $h_{f}$ & 202,700 & $9,855,331$ & $198,563,366$ & $1,344,090,821$ \\
\hline number_sph & 226,100 & $10,914,912$ & $240,024,669$ & $2,071,653,076$ \\
\hline \multicolumn{5}{|c|}{ General demography $15+$} \\
\hline population $_{f}$ & 447,189 & $20,876,809$ & $389,932,647$ & $2,750,154,246$ \\
\hline population $_{m}$ & 366,546 & $17,273,031$ & $357,943,440$ & $2,750,152,789$ \\
\hline \multicolumn{5}{|l|}{ Simple gender indices } \\
\hline GPI & 0.90 & 0.90 & 0.83 & 0.65 \\
\hline$A G G$ & 23,400 & $1,059,581$ & $41,461,303$ & $727,562,255$ \\
\hline$G A I$ & -0.05 & -0.05 & -0.09 & -0.21 \\
\hline$G P I_{\text {sph }}$ & 0.73 & 0.75 & 0.76 & 0.65 \\
\hline$A G G_{s p h}$ & 0.16 & 0.16 & 0.16 & 0.26 \\
\hline$G A I_{s p h}$ & -0.15 & -0.14 & -0.14 & -0.21 \\
\hline
\end{tabular}

From Table 3 we see that, similarly to the previous case, for a large data array (the world) the indices GAI and GPI $I_{s p h}$ produce the same results, as do the indices GPI and $G P I_{s p h}(0.65$ and -0.21 respectively). Again, this similarity is not observed in the smaller data arrays. In the Kirovohrad region and in Ukraine, the difference between the indices is: for the indices GPI and GPI sph, $0.15-0.17$; and for the indices GAI and $G P I_{s p h}, 0.09-0.10$. Slightly lower differences are observed between indices for Europe \& North America; 0.07 and 0.05 respectively. In this case, for the whole world data array, the calculation of the gender parity and gender asymmetry indices for economically active individuals within the population aged $15+$ can be performed using both formulas (7) and (9) and formulas (11) and (13) (again, it is a requirement that population $_{m} \approx$ population $_{f}$. For the calculation of the same indices for economically active individuals within the population aged $15+$ in other regions (which have smaller data arrays), it is expedient to use formulas (7) and (9).

In selecting one formula or another to calculate gender parity or gender asymmetry, it is necessary to assess the overall demographic indicators of the region under research. From formulas (7) and (9) it is clear that the closer the general demographic indices of men and women (i.e. population $_{m} \approx$ population $_{f}$, the closer the results 
of formulas (7) and (9) will be to the results of formulas (11) and (13). Let us analyse the values of the formula

$$
G A I=\frac{\text { population }_{f}-\text { population }_{m}}{\text { population }_{f}+\text { population }_{m}}
$$

for demographic indicators of both populations (Table 4).

Table 4

Assessment of gender asymmetry in values population $_{f}$ and population ${ }_{m}$ calculated on total population and population aged $15+$ by region

\begin{tabular}{|c|c|c|c|c|}
\hline Denomination & $\begin{array}{l}\text { Kirovohrad } \\
\text { region }\end{array}$ & Ukraine & $\begin{array}{c}\text { Europe \& } \\
\text { North America }\end{array}$ & The world \\
\hline \multicolumn{5}{|c|}{ General demography (example 1) } \\
\hline population $_{f}$ & 539,900 & $24,549,634$ & $620,365,541$ & $3,516,939,678$ \\
\hline populationm $_{m}$ & 456,100 & $21,043,666$ & $588,555,526$ & $3,580,460,987$ \\
\hline \multicolumn{5}{|c|}{ General demography $15+$ (example 2$)$} \\
\hline population $_{f}$ & 447,189 & $20,876,809$ & $389,932,647$ & $2,750,154,246$ \\
\hline population $_{m}$ & 366,546 & $17,273,031$ & $357,943,440$ & $2,750,152,789$ \\
\hline \multicolumn{5}{|l|}{ Ratio value (4) } \\
\hline Example 1 & $8.4 \mathrm{E}-2$ & 7.7 E-2 & 2.6 E-2 & $-8.9 \mathrm{E}-3$ \\
\hline Example 2 & $9.9 \mathrm{E}-2$ & 9.4 E-2 & 4. $3 \mathrm{E}-2$ & $2.65 \mathrm{E}-7$ \\
\hline
\end{tabular}

Example 1 tests the entire population of each region and example 2, the population aged 15 or older. For the whole world, in the first and second cases the asymmetry between the values population $_{f}$ and population $_{m}$. (i.e. the numbers of men and women in the relevant population) is less than $1 \%$ of the total population of the corresponding group. For the other regions, the asymmetry values are significantly higher, ranging from approximately $2 \%$ to $10 \%$.

\section{Conclusions and prospects for further research in the field of study}

The study of the results of simple gender indices makes it possible to state that the analysis of gender parity/asymmetry requires separate methodological approaches to demographic statistics and social statistics.

1. For the calculation of simple gender indices of demographic statistics, the application of the gender parity index formula (2) and gender asymmetry index formula (4) are correct and universally applicable.

2. For the calculation of simple gender indices of social statistics, the gender parity index formula (11) and gender asymmetry index (13) are not universally applicable. Instead, it is correct to use the formulas for specific gender parity index (7) and

Regional Statistics, Vol. 8. No. 2. 2018: 170-183; DOI: 10.15196/RS080205 
specific gender asymmetry index (9), which take into account demographic indicators population and $_{\text {and }}$ population $m_{m}$.

3. In cases where population $_{m} \approx$ population $_{f}$, the necessary accuracy of the calculations can be achieved. See formula (10) and table 4). The application of the formulas for the gender parity index (11) and gender asymmetry index (13) in social statistics can be considered completely correct.

\section{Acknowledgement}

The article has been prepared in the framework of the Erasmus+ project "Gender Studies Curriculum: A Step for Democracy and Peace in EU-Neighbouring Countries with Different Traditions", No. 561785-EPP-1-2015-1-LT-EPPKA2-CBHE-JP. This project has been funded with support from the European Commission. This publication reflects the views of the author only, and the Commission cannot be held responsible for any use which may be made of the information contained therein.

\section{REFERENCES}

AKBASH, K.-PASICHNYK, N.-RIZHNIAK, R. (2017a): Identification of Indicators of Distribution of Gender Groups According Special Features Statistics of Ukraine 77 (2): 6-12. (in ukr).

AkBAsh, K.-PASichnYK, N.-Rizhniak, R. (2017b): The Analysis of Survey among Students on Gender Issues Applying Indicators of Specific Asymmetry Scientific, Theoretical, Public and Political Literary Miscellany «Grani» 20 (6/146): 5-16 (in ukr).

AKBASH, K.-PASICHNYK, N.-RIZHNIAK, R. (2017c): Identification of Distribution Indicators of Specific Features in Gender Groups (on the example of faculty students) Scientific Works of Kirovohrad National Technical University. Economic Sciences. Kropyonytskyi: CUNTU 31: 236-244 (in ukr).

Anisimova, N. V. (2015): Assessment of the Functional Asymmetry Applying Various Methodological Approaches International Scientific and Research Journal 7 (38): 70-74 (in rus).

Bhattacharya, S. (2013): Gender Parity Index in Primary Education in West Bengal Vidyasagar University Journal of Economics 17 (2012-139): 105-117.

Department of Statistics IN Kirovohrad REGION (DSKR) (2016): Women and men in Kirovohrad region. Statistical book (in ukr), Kirovohrad.

EUROPEAN INSTITUTE FOR GENDER EQUALITY (2017): Gender Equality Index (GEI) Methodological Report, Vilnus. (downloaded: 2018. July)

http://eige.europa.eu/rdc/eige-publications/gender-equality-index-2017methodological-report

JanA, M.-KhAN, A.-ChatTerJeE, S.-SAR, N.-DAS, A. (2014): Variability of Transition Rate and Gender Parity in Rural Primary School Level in Gopiballavpur Circle (West), Paschim Medinipur, West Bengal: A Case Specific Study Creative Education 5: 2041-2056. https://doi.org/10.4236/ce.2014.524228

Regional Statistics, Vol. 8. No. 2. 2018: 170-183; DOI: 10.15196/RS080205 
Huebler, F. (2008): Beyond Gender: Measuring Disparity in South Asia using an Education Parity Index Issues Paper. UNICEF ROSA/UNGEI, Kathmandu.

Herbut, N. A. (2012): Theoretical and Methodological Grounds of Gender Studies Scientific Papers of Kuras Institute of Political and Ethnic Studies 1: 344-361 (in ukr).

Pidhornyi A. Z.-Samotoenkova O. V.-Olvinska Yu.O.-Vitkovska K. V. (2016): Social and Demographic Statistics: Textbook Kiev.(in ukr).

Shorokhova I. S.-KisLyAK N. V.-MARIEV O. S. (2017): Statistical Methods of Analysis: study guide Publishing House Ural Un-ta, Ekaterinburg.(in rus)

Uzzoli, A. (2016): Health inequalities regarding territorial differences in Hungary by discussing life expectancy Regional Statistics 6 (1): 139-163. https://doi.org/10.15196/RS06108

UNESCO INSTITUTE FOR STATISTICS (UIS) (2009): Education Indicators Technical Guidelines [Montreal. http://uis.unesco.org/sites/default/files/documents/educationindicators-technical-guidelines-en_0.pdf (downloaded: July 2018)

United NAtions ECONOMic COMmission FOR EUROPE (UNECE) (2012): Statistical database. Indicator enrolment in primary education Available at: http://data.uis.unesco.org/

United NATIONS ECONOMIC COMMISSION FOR EUROPE (UNECE) (2016): Using gender statistics: $A$ toolkit for training data users Available at: http://www.unece.org/stats/gender/toolkit

United NATIONS EDUCATIONAL, SCIENTIFIC AND CUltural Organization (UNESCO) (1999): Gender-sensitive Education Statistics and Indicators: A practical guide, Paris. http://unesdoc.unesco.org/images/0010/001091/109177eo.pdf

United Nations Educational, Scientific and Cultural Organization (UNESCO) (2017): UNESCO Regions

http://www.uneso.org/new/en/unesco/worldwide/europe-and-north-america/

WORLD BANK (WB) (2017): World Development Indicators https://data.worldbank.org/indicator/SP.POP.TOTL?view= chart

WORLD ECONOMIC FORUM's (WEF) (2016): The Global Gender Gap Report http://www3.weforum.org/docs/GGGR16/WEF_Global_Gender_Gap_ Report_2016.pdf

Regional Statistics, Vol. 8. No. 2. 2018: 170-183; DOI: 10.15196/RS080205 